\title{
Inteligência e complexidade - a propósito de idéias de Hillis
}

\section{Pedro Demo*}

\begin{abstract}
Resumo Um dos espaços privilegiados para estudo da capacidade humana de aprender é o da inteligência artificial. Embora esteja marcado, historicamente, pela expectativa mecanicista do representacionismo direto, tem evoluído muito nos últimos tempos, à luz de acerbo debate, nem sempre bem comportado. Seja como for, eis uma questão que tem atraído a atenção e fúria de muitos pesquisadores: poderiam as máquinas tornar-se inteligentes, talvez mais inteligentes que os seres humanos? Neste texto breve e introdutório, indicamos alguns traços desta discussão, tomando como fulcro o livro de Hillis (1998) sobre as promessas do computador, cada vez mais capaz de unir complexidade e inteligência.
\end{abstract}

Palavras chave Hillis, inteligência humana, inteligência artificial

\begin{abstract}
One of the main fields for the study of human learning capacity is that of human intelligence. Although historically marked by the mecanicist expectation of direct representationism, it has evolved in recent times, in the light of acerbic, and not always wellbehaved, debate. At any rate, here is an issue which has attracted the attention and the fury of many researchers: could machines become intelligent, maybe more intelligent than human beings? In this brief and introductory text, we indicate a few features of this discussion, building on the book written by Hillis (1998) on the computer's promisses.more and more capable of uniting complexity and intelligence.
\end{abstract}

Keywords Hillis, human intelligence, artificial intelligence

Um dos espaços privilegiados para estudo da capacidade humana de aprender é o da inteligência artificial. Embora esteja marcado, historicamente, pela expectativa mecanicista do representacionismo direto, tem evoluído muito nos últimos tempos, à luz de acerbo debate, nem sempre bem comportado. Aplica-se aqui a descoberta de Collins (1998), ao estudar a "sociologia das filosofias", passando também por ambientes acadêmicos não ocidentais e de eras passadas (inclusive orientais), de que o motor principal da inovação científica é a crítica, sem esquecer a intriga. A noção corrente de "comunidade acadêmica" é irônica, porque é um dos lugares onde existe menos espírito comunitário. Predomina a competitividade, muitas vezes exacerbada, o que também mostra o parentesco extraordinário entre conhecimento e poder, inclusive mercado. Em sua "arqueologia' - como diria Foucault - conhecimento gosta de falar da verdade, mas namora mesmo o poder. Seja como for, eis uma questão que tem atraído a atenção e fúria de muitos pesquisadores: poderiam as máquinas tornar-se inteligentes, talvez mais inteligentes que os seres humanos? Kurzweil (1999) já aposta na supremacia do computador, em seu livro sobre as "máquinas espirituais", tendo como subtítulo "quando os computadores excedem a inteligência humana". Neste texto breve e introdutório, queremos apenas indicar alguns traços desta

*Pós-doutor pela University of California at Los Angeles (UCLA), professor do Departamento de Sociologia/UnB 
discussão importante, tomando como fulcro o livro de Hillis (1998) sobre as promessas do computador, cada vez mais capaz de unir complexidade e inteligência.

\section{Posicionamento de Hillis}

Um dos traços mais marcantes do pensamento de Hillis é a combinação entre o simples e o complexo, além da intimidade com que fala do assunto, por ser, ele mesmo, emérito criador de softwares. Para ele os "computadores são os objetos mais complexos que os seres humanos já criaram, mas em sentido fundamental são marcantemente simples", também por conta da "regularidade do desenho do computador" (HILLIS, 1998). Existe "hierarquia das partes", "usualmente uni-direcionais", mas, o que surpreende sobretudo é que "dependem mais de idéias do que de tecnologia". "Uma das coisas mais marcantes sobre computadores é que sua natureza essencial transcende a tecnologia". Em termos sucintos, algumas idéias sobre a natureza do computador poderiam ser: a) abstração funcional - que "desgruda as idéias, da tecnologia", permitindo que a base material seja ultrapassada para além da mera quantidade; b) computador universal - existe somente uma espécie de computador, todos são iguais no que podem fazer, sugerindo-se que "fazer computador pensar como o ser humano é apenas questão de programar corretamente"; c) a antítese disso: poderá existir desenho totalmente diferente do atual - rumo à complexidade, pois "os próprios princípios que possibilitaram do desenho dos computadores levaram em última instância a certa fragilidade e ineficiência" (HILLIS, 1998, p. 9); neste caso funcionaria a analogia com o cérebro: "sistema no qual os comportamentos do sistema emergem da acumulação de muitas interações simples, sem qualquer controle de cima para baixo". Afirma que costumamos subestimar o potencial do computador, principalmente quando o degradamos à máquina de escrever mais sofisticada, pois o "verdadeiro poder do computador está em que é capaz de manipular não apenas a expressão das idéias, mas também as próprias idéias". É equipamento que "acelera e estende nosso processo de pensamento; é máquina de imaginação" (HILLIS, 1998, p. 8).

Um dos grandes desafios é reduzir uma tarefa a suas funções lógicas e implementá-las como circuito de impulsos conectados. Parte-se do ponto de vista que toda tarefa possui alguma estruturação comandada por certas funções lógicas. Se estas forem adequadamente reconstruídas no silício, seus circuitos produzem mais do que reflexos mecânicos. "Computação gira em torno de realizar tarefas que parecem ser complexas, partindo-as em operações simples" (HILLIS, 1998, p. 4). Trata-se de examinar e descobrir padrões seqüencialmente no tempo e no espaço, dentro da expectativa de que toda dinâmica possui modos recorrentes de funcionar. "O computador representa números, letras e qualquer outra coisa com padrões de bits" (HILLIS, 1998 , p. 11), não para sugerir apenas representação mecânica, mas o mundo das idéias que estaria por trás. Dentro de seu característico entusiasmo, Hillis afirma: "Sempre que desenho chip, a primeira coisa que quero fazer é olhar no microscópio - não porque penso que posso aprender alguma coisa nova olhando, mas porque fico sempre fascinado como um padrão pode criar realidade" (1998, p. 16). Por trás desta "fascinação" há um mundo de questões fundamentais, a começar pelo fenômeno da emergência, através do qual a organização de quantidades aparentemente simples pode produzir qualidades extremamente complexas. Tomando o cérebro como exemplo, é constituído fisicamente de matéria orgânica como outra qualquer, digamos, massa cinzenta. Nela pululam os mesmos elementos físicos - átomos, moléculas - encontrados em qualquer matéria. Entretanto, daí saem pensamento, consciência, esperança, emoção, entidades qualitativas, que certamente não podem ser reduzidas a dinâmicas materiais mecânicas, mas partem delas iniludivelmente. Por trás do pensamento há base material organizada de certa maneira, que, segundo o próprio Searle (1998) diz, "causa" o pensamento, 
embora não se possa reduzir pensamento à massa cinzenta, bem como não se pode reduzir emoção à adrenalina. Quando a ciência "analisa" (decompõe) o cérebro no laboratório, não encontra, nos instrumentos que hoje temos de observação e pesquisa, pensamento, mas apenas matéria orgânica de certa tessitura.

Talvez tenhamos noção equivocada da distinção entre quantidade e qualidade, porque a natureza parece mostrar que são apenas faces da mesma realidade, uma encravada na outra. Como diria Prigogine, também a realidade natural é dinâmica, dialética, é autenticamente um "vir a ser", no fundo sujeito histórico buscando seu lugar próprio, irreversível por conta da "flecha do tempo", vivo (PRIGOGINE, 1996; PRIGOGINE; STENGERS, 1997). Não sabemos ainda quase nada desta passagem estonteante, chamada emergência, através da qual elementos simples materiais, dispostos de determinada ordem ou configuração, produzem fenômenos de outra ordem, completamente diferentes. Para a educação, a mensagem mais forte talvez fosse que sequer a natureza se repete, reproduz. A matéria mistura-se para inovar. A tabela atômica nos oferece desenho limitado, aparentemente simples e repetitivo, mas misturando-se os elementos, surgem deles todas as variedades de realidade, em eco praticamente infinito. Se o computador encontrar um dia este caminho, poderá tornar-se inteligente, já que o pensamento não é fenômeno do outro mundo, mas resultado da dinâmica material do cérebro.

Algumas coisas importantes os computadores já fazem, como a expectativa de que a "tecnologia da implementação deve produzir outputs perfeitos a partir de inputs imperfeitos, limpando pequenos erros na coisa", expressando já certa capacidade de seleção da informação. A "estrutura hierárquica da abstração é a ferramenta mais poderosa para entender sistemas complexos, porque deixa-nos focar num aspecto simples do problema cada vez" (HILLIS, 1998, p. 19). Quer dizer, a complexidade não é apenas estruturada, mas hierarquicamente estruturada, mostrando, dentro da complexidade, certa ordem. É mister encontrar tais padrões recorrentes e que comandam a dinâmica do processo. "Uma das razões por que as máquinas de estado finito são tão úteis é que podem reconhecer seqüências" (HILLIS, 1998, p. 35). Só o ser humano é mais adaptável que o computador, segundo Hillis, chegando a reconhecer o lado poético de sua linguagem computacional. "Um programa bem escrito de computador possui estilo, fineza e mesmo humor - e claridade que rivaliza com a melhor prosa" (HILLIS, 1998, p. 50).

Considera infundado o medo de que o computador ameace "nossa posição única de seres racionais" (HILLIS, 1998, p. 61), basicamente porque se trata de "inteligências" diferentes, em particular do ponto de vista da evolução. "Turing mostrou que todo cálculo pode também ser realizado por um leigo estúpido, embora meticuloso, que siga um conjunto simples de regras para ler e escrever a informação" e ainda que este leigo possa ser substituído por máquina de estado finito" (HILLIS, 1998p. 63). Porquanto, na tarefa de calcular, o que fazemos é seguir regras que realizam as sequiências do cálculo. A rigor, não inventamos nada de novo, a não ser a capacidade do raciocínio dedutivo completo, o que, certamente, não é pouca coisa. Quem "decora" o cálculo, não deduz. Mas quem sabe fazer o raciocínio adequado, "saca" as seqüências e as ordena, passo a passo, até ao resultado final. Turing "sugere que um computador universal com programação apropriada poderia ser capaz de simular a função do cérebro humano" (HILLIS, 1998, p. 64), ainda que esta expectativa se baseie na pressuposição de que o cérebro funcione como computador, o que ainda é algo bastante discutível. Basta olhar para o fato de que o computador é máquina tipicamente binária, enquanto muitos estariam dispostos a definir inteligência mais como lógica difusa, do que binária, sobretudo não linear. Hillis sustenta, por sua vez, que um computador com três estados - para ultrapassar a condição binária - pode sempre ser reduzido a binário, "pois é possível simular um usando o outro" (HILLIS, 1998, p. 64), ou seja, o ordenamento da realidade, seguindo os padrões, é binário. "Um verdadeiro contínuo é irrealizável no mundo físico" (HILLIS, 1998, p. 65), pois é sempre feito de partes decomponíveis, analisáveis, como mostra a realidade atômica. 
O problema é que o todo é maior que a soma das partes. Decompondo o todo parte por parte, não encontramos algo diferente, assim como decompondo a massa cinzenta neurônio por neurônio, não encontramos pensamento, embora tenhamos certeza de que pensamento seja algo tão real como o neurônio. É interessante notar que a computação se curva ao signo no fundo positivista da ciência, apostando que só entendemos a variação, se descobrimos como invariavelmente varia... A dinâmica, como movimento contínuo, não é inteligível, a rigor, a menos que a consigamos decompor em pedaços, padrões, seqüências. Na verdade, a ciência só entende o que consegue formalizar, ou seja, colocar dentro de parâmetros lógicos. Todos os seus métodos, inclusive a dialética, são "lógicos". A dialética, à diferença da lógica formal, procura abrir espaços para expressões menos formalizáveis, quando usa questionários abertos, histórias de vida, depoimentos, conversas gravadas, etc., mas, no fundo, quando pretende analisar as informações, tem que ordená-las logicamente, formalizando-as. No computador, a capacidade de formalização atinge seu ápice, porque toda informação é expressa binariamente (ou 0 ou 1). Chama de "pseudoprobabilidade" dos números prováveis sua tessitura caótica, podendo produzir resultados imprevistos a partir de um conjunto determinista. Esta característica recomenda aceitar que há coisas incomputáveis, como, por exemplo, o problema da parada no computador. Assim, o processamento computacional não pode "resolver tudo", porque uma coisa é a maneira que tem de processar informação, outra coisa é o mundo real, muito mais caótico que binário. Hillis lembra, então, o célebre teorema da incompletude de Gödel.

O teorema de Gödel estatui que dentro de todo sistema matemático autoconsistente, suficientemente poderoso para expressar a aritmética, existem proposições que não podem nem ser provadas como verdadeiras nem falsas. Os matemáticos viam seu negócio como sendo o de provar ou desaprovar proposições, e o teorema de Gödel provou que seu 'ofício' era, em certas instâncias, impossível (HILLIS, 1998, p. 70).

Esta descoberta abalou o mundo das ciências naturais, estando esses dois autores - Turing e Gödel - talvez entre os dois maiores gênios do século XX. ${ }^{1} \mathrm{O}$ primeiro trouxe a expectativa fantástica de poder computar quase sem limites, enquanto outro a cautela de que o conhecimento é procedimento intrinsecamente limitado. Seja como for, qualquer proposição provada pelo matemático poderá ser provada pelo computador, ainda que "estatisticamente falando, a maioria das funções matemáticas não sejam computáveis” (HILLIS, 1998, p. 71).

Seguindo sugestão de Penrose, renova a expectativa sobre a física quântica, como talvez mais adequada para entender o cérebro (PENROSE, 1994). O computador atual ainda pretende formalizar tudo, de modo tendencialmente binário, linear. As seqüências pseudoprobabilísticas produzidas pelo computador parecem aleatórias, mas há algoritmos subjacentes que as geram. "Não são verdadeiramente aleatórias, por causa das leis da física". "Na física quântica produzem-se efeitos que são puramente aleatórios" (HILLIS, 1998, p. 71). Assinala o fenômeno do "entanglement" - "quando medimos alguma característica de uma das partículas, isto afeta o que medimos em outra, mesmo se estão fisicamente separadas" (HILLIS, 1998, p. 73). O funcionamento do cérebro humano poderia assemelhar-se mais à física quântica, no sentido de saber lidar com situações caóticas, praticar saltos emergenciais, fazer da incerteza fundamento da criatividade, em particular lidar com a ambigüidade e a interpretação. Entretanto, Hillis acredita que o computador poderá, um dia, chegar a trabalhar tais níveis de complexidade. "As limitações teóricas dos computadores não garantem nenhuma linha divisória útil entre seres humanos e máquinas. Até onde conhecemos, o cérebro é espécie de computador, e pensamento é precisamente computação complexa" - tal qual a vida seria "reação química complexa" (HILLIS, 1998, p. 75). "Identificamos os componentes corretos, mas ignoramos o mistério. Para

\footnotetext{
${ }^{1}$ Veja estudo interessante sobre gênios "não lineares", entre eles Gödel, de Hofstadter (2001).
} 
mim, a vida e o pensamento são, ambos, algo absolutamente maravilhoso, porque efetivam o fato de que emergem de partes simples, compreensíveis" (HILLIS, 1998, p. 76).

Capítulo fundamental da formalização computacional é sempre sobre o algoritmo, definido como "procedimento seguro contra falha, garantido para chegar até fim específico. Trata-se de sequiência de operações, de caráter recorrente. Representa a face tipicamente formalizável, ainda que isto não signifique o congelamento da realidade, como queria o estruturalismo original. Buscam-se recorrências da dinâmica, que traduzem as evoluções do fenômeno. Podem, pois, ser estruturas da dinâmica. No outro lado, aparece fenômeno contrário: "regra que tende a dar resposta correta, mas não é garantida, chama-se heurística (HILLIS, 1998, p. 83). Esta também formaliza, mas está alerta para o fato de que "tudo que é sólido, balança no ar", como diria Berman (1986). Faz da insegurança o ambiente natural da vida, porque é dele que se pode criar, saltar, chegar a outros lados. Faz pouco caso dos "filósofos" que, por vezes sem conhecimento adequado, discursam impropriamente sobre computadores, geralmente impondo limites de toda ordem. Quando são ultrapassados por novos fatos, inventam outros argumentos, filosofando àtoa. Esta crítica áspera é comum entre os pesquisadores mais duros ligados à inteligência artificial, bastando lembrar sua reação a discussões inauguradas por Dreyfus (1997), Searle (1998) ou Sfez (1994). Ainda assim, reconhecem problemas ligados à "explosão combinatória", muito acentuado, por exemplo, por Norretranders (1998), e que significa a complexificação exponencial de procedimentos, por vezes partindo-se de componentes simples. Na vida concreta, porém, "há muitos problemas para os quais não necessitamos resposta exata toda vez" (HILLIS, 1998, p. 90).

"Estamos nos aproximando dos limites do quanto podemos aumentar a velocidade do computador sem mudar o desenho básico" (HILLIS, 1998, p. 109). Esta idéia acena para a expectativa de que é mister mudar alguma coisa profundamente no computador, para ir além dos formatos atuais. "Para trabalhar mais rápido, os computadores de hoje precisam fazer mais que uma operação cada vez" (HILLIS, 1998, p. 109), o que leva ao conceito de "rede de computadores". "Os computadores eram lentos porque eram sequienciais; podem fazer só uma coisa de cada vez. Computador precisa ver a imagem ponto por ponto; ao contrário, o cérebro percebe imagem inteira instantaneamente e pode ao mesmo tempo comparar o que vê em cada imagem que conhece" (HILLIS, 1998, p. 109, p. 114). Vamos precisar de máquinas que poderão ler seus inputs diretamente do mundo físico, mais do que depender de intermediários humanos. Enquanto a informação disponível na Internet se tornar mais rica, e os tipos de interação entre os computadores conectados se tornar mais complexo, espero que a internet comece a exibir comportamento emergente indo além do que tem sido explicitamente programado no sistema" (HILLIS, 1998, p. 120).

No fundo, Hillis postula a possibilidade de um computador já capaz de interpretar a realidade, não apenas de formalizá-la binariamente, não muito diferente da expectativa de Kurzweil. Segundo este autor, os computadores do futuro serão "máquinas espirituais", necessitarão de corpo, e, como diz Picard, saberão sentir emoções (1999).

Os programas de computador que tenho descrito até agora operam de acordo com regras fixas supridas pelo programador. Não possuem nenhum modo para inventar novas regras por si mesmos, ou de melhorar aquelas que foram dadas [...] Fazem o que foram programados para fazer [...] (HILLIS, 1998, p. 121). 
Mas nem todos são assim inflexíveis. Com o tempo, precisam fazer uso do feedback de maneira criativa e interpretativa. "O sistema de feedback ajusta a resposta, de acordo com o erro, para conseguir o objetivo" (HILLIS, 1998, p. 122). Em vista disso, o futuro estaria nas redes neuronais, já que "rede neuronal é rede simulada de neurônios artificiais", à semelhança da tessitura e funcionamento do cérebro. Componente fundamental será o perceptron que pode aprender a reconhecer padrões.

Segundo Hillis, poucos teriam imaginado que processo tão complexo como o pensamento poderia ser partido em operações implementáveis por máquina.

A pressuposição é que se inteligência fosse alguma vez criada, seria por processo emergente - ou seja, por processo no qual o comportamento complexo emerge como consequiência global de bilhões de interações pequenas locais. Assumiu-se que aquilo de que o maquinador precisa não era o diagrama correto de montagem, mas a receita correta, de acordo com a qual os ingredientes organizariam a si mesmos com inteligência. Tal processo permitiria que inteligência fosse criada sem a compreensão do maquinador de como o processo - ou a própria inteligência - funcionaria exatamente (HILLIS, 1998, p. 138).

Admite que esta noção pré-científica pode ser a pertinente: seremos capazes de criar inteligência artificial muito antes de compreender a inteligência natural; o processo de sua criação mostrará que a inteligência emerge de séries complexas de interações que ainda não entendemos bem; esta criação estará mais próximo de como se faz um bolo ou se cultiva um jardim, do que de inventar uma máquina. $\mathrm{O}$ maior feito da tecnologia seria a criação de ferramentas que nos facultam ir além da engenharia, ou seja, criar mais do que podemos compreender.

Bem interessante esta expectativa, que diminui muito o laivo positivista, porque deixa de lado a formalização completa da realidade, ponto por ponto, de estilo somativo, para fixar-se na possibilidade de descobrir procedimentos inteligentes que ainda não devassamos pelo métodos normais da ciência analítica. Com efeito, tomando a sério a complexidade da realidade, é mister andar no meio dela sem ter, jamais, noção clara de tudo. Catamos padrões, para obtermos algum norte, termos alguma idéia de onde estamos, podermos voltar para o mesmo lugar sem se perder por completo, tateando, nos aproximando, fazendo, por outra, da incerteza o manancial da flexibilidade criativa. O cérebro tem $10^{12}$ neurônios e cada neurônio com, em média, $10^{5}$ conexões, ou seja, detém complexidade estonteante, capaz, por isso mesma, de lidar melhor com a complexidade. "O cérebro é, até certo ponto, sistema auto-organizado" (HILLIS, 1998, p. 139). Há mais ou menos 50 áreas, sendo que o lado esquerdo e direito, no microscópio, parecem iguais, mas cumprem funções diferentes.

O ponto importante aqui é que o cérebro não é apenas muito complicado, mas igualmente muito diferente na estrutura de uma máquina inventada pela engenharia. Isto não significa que não podemos nunca inventar uma máquina para realizar as funções do cérebro humano, mas significa que não podemos esperar compreender inteligência desfazendo-a em pedaços e analisando-a como se fosse máquina desenhada hierarquicamente... Na engenharia, a maneira de lidar com complexidade é desfazendo em pedaços (HILLIS, 1998, p. 141).

Sistemas hierárquicos, todavia, são frágeis, porque rigidamente amarrados e dependentes. Em sistemas complexos, porém, mesmo partes funcionando corretamente podem produzir comportamentos inesperados, quando interagem, de um lado, mas, de outro, também produzir efeitos compensatórios de equilíbrio, aproximações flexíveis e cada vez mais finas, correção de erros. "Nenhuma pessoa isolada compreende sistema complexo em operação" (HILLIS, 1998, p. 147). Mas, mesmo se não soubermos explicar, não quer dizer que sejam menos confiáveis. $O$ cérebro tem, sobre a máquina, a vantagem da evolução e da aprendizagem. 
As forças de maturação da morfogênese levam as células nervosas a crescer em padrões corretos, e o processo de aprendizagem afina as conexões. O estágio final da aprendizagem do cérebro é processo cultural, no qual conhecimento adquirido por outros indivíduos através de muitas gerações é transferido para dentro dele (HILLIS, 1998, p. 148).

Quando se combina evolução com desenvolvimento, evolução ocorre mais rápida - "os processos adaptativos do desenvolvimento podem consertar as falhas num desenho evolucionário imperfeito" (HILLIS, 1998, p. 149). Outro efeito que reduz radicalmente o tempo requerido para desenvolver um comportamento complexo é a "instrução".

Um bebê humano pode desenvolver inteligência pelo menos em parte porque tem outros humanos de quem aprender. Parte de sua aprendizagem é adquirida por pura imitação, e parte através de instrução explícita. Linguagem humana é mecanismo espetacular para transferir idéias de uma mente para outra, permitindo-nos acumular conhecimento útil e comportamento através de muitas gerações em proporção que supera de muito a evolução biológica. A "receita" para inteligência humana está tanto na cultura humana quanto perfaz o genoma humano (HILLIS, 1998, p. 151).

"Em certo sentido, cérebro é espécie de máquina", mas "creio que jamais teremos perfeito entendimento do que é pensamento" (HILLIS, 1998, p. 152).

\section{Inteligência e aprendizagem}

Começando pelo fim, Hillis valoriza a função de "instrução", mas não em sentido instrucionista, pois, no fundo quer apontar para a vantagem do cérebro humano sobre a máquina, já que tem por trás de si tanto processo favorável de evolução, quanto de aprendizagem. Olhando bem o fenômeno da emergência, significa sempre algo inovador, porque os elementos de origem nunca são os mesmos no resultado final. Ou melhor, podem ser os mesmos como elementos, mas organizam-se de tal forma que geram outro fenômeno, por vezes, totalmente diverso. $\mathrm{O}$ que encanta Hillis na computação é sobretudo este salto surpreendente, porquanto um padrão desenhado no silício é capaz de gerar produtos de outra ordem, passando da quantidade para a qualidade de maneira incrível. Por certo, este autor também está ligado ao pano de fundo da inteligência artificial, às vezes tendencialmente positivista, mas tem a marca inequívoca da visão crítica e o senso agudo pela flexibilidade criativa da inteligência.

Esta maneira de ver sugere, na prática, que a "inteligência" do computador será de outra ordem, porque gerada de outra maneira. A "inteligência" humana é o resultado de processo evolucionário muito extenso e intenso, além da capacidade de aprender, o que teria acarretado finezas, sensibilidades, jeitos que um computador não poderia gerar. Não se quer dizer que inteligência só possa ser aquela engendrada por processo biológico e histórico. Cada vez menos se nega ao computador a possibilidade de tornar-se inteligente, ainda que seu desempenho hoje esteja muito longe disso, como regra. Mas abrigará possivelmente a inteligência que uma máquina pode engendrar, menos próxima do fundo cultural hermenêutico, menos interpretativa por falta de memória histórica não apenas acumulada, mas sobretudo aculturada. Por isso, em vez de visualizar uma competitividade entre inteligência computacional e humana, é melhor perceber sua complementaridade, até porque haverá sempre muita coisa em comum, pelo próprio fato de que seu arquiteto é o cérebro humano. Entretanto, o cérebro é capaz de fazer coisas maravilhosas, das quais não possui entendimento adequado, do mesmo jeito que nossa vida "maravilhosa" é em grande parte inconsciente. Por outra, não será o caso fechar qualquer porta à 
inteligência artificial, porque todas, até ao momento, foram arrombadas. Assim, se, de uma parte, suas promessas foram quase sempre excessivas, de outra, vão se realizando aos poucos e em direções não previstas.

É interessante notar que mesmo o representacionismo, tão comum na inteligência artificial, não se sustenta, diante dos argumentos da complexidade. O próprio computador, sobretudo em suas versões mais recentes de estilo neuronal, mostra que é impossível a representação direta, meramente reprodutiva, porque, ao processar informação, estabelecem-se novas conexões que não são apenas somativas lineares. A capacidade de ler padrões ou algoritmos na dinâmica dos dados indicaria também que o processamento não é mero espelho que apenas reflete. Isto está longe de ser algo similar à interpretação culturalmente plantada como faz o cérebro, porque o computador não tem passado cultural nem é - pelo menos ainda - equipamento hermenêutico. A biologia vem confirmando esta perspectiva com grande vigor. Primeiro, ao nível dos próprios sentidos, digamos da visão, a realidade externa é captada seletivamente, tanto correspondendo à capacidade contextuada evolucionária e historicamente de captar, quanto correspondendo à necessidade de filtrar, da massa de dados, aqueles que teriam relevância. Não vemos qualquer coisa, mas o que podemos ver de acordo com nosso aparelho da visão e sobretudo o que mais nos interessaria. Neste plano já aparece certa capacidade interpretativa, sobretudo no horizonte das relevâncias seletivas. Segundo, transportando o resultado da visão para o cérebro, ocorre em plenitude o fenômeno emergencial da interpretação hermeneuticamente contextuada, a começar pelo sentido, significado das coisas. Surgem as metáforas, através das quais a mesma palavra expressa significados múltiples e criativos, dentro de uma flexibilidade marcante capaz de perceber silêncios que falam e falas que nada dizem. A linguagem é feita dessas coisas em seu nível semântico, que ultrapassa enormemente o nível sintático. Para entender bem uma língua é mister estar dentro de seu contexto cultural, onde cada palavra, frase ou dito adquire significado concreto. Foi neste sentido que o projeto de traduzir em computador é ainda algo muito preliminar, porque este não possui a capacidade de interpretar, fazendo, por isso, traduções "quadradas". Este é também o problema da "autocorreção" dos textos, que somente corrige a sintaxe mais simples ou meros erros ortográficos. Embora isto já seja de grande valia, está muito longe de corrigir o texto em termos semânticos.

Ainda mais interessante é perceber que Hillis aceita a tese de que provavelmente jamais saberemos o que é pensamento. Conhecemos já que provém do cérebro, sabemos alguma coisa do próprio cérebro, mas ainda não descobrimos o mistério: como os neurônios se organizam e agem para resultar pensamento... Talvez a máquina não possa fazer isso, porque lhe falta a referência histórica da evolução multimilenar. Não é, pois, apenas problema de engenharia analítica, que, descobrindo as partes, as remonta, dando conta do todo. Se o todo fosse apenas as partes, sim. Acontece que na realidade, os todos são mais que a simples soma das partes. $\mathrm{O}$ fenômeno da emergência mostra saltos estonteantes: as mesmas partes, organizadas de certa maneira, produzem fenômenos totalmente diversos. Torna-se complicado - talvez impossível fazer a engenharia reversa, porque, ao decompor as partes, ficamos apenas com estas, desaparecendo o todo e suas propriedades diferentes das partes. Não se trata de imaginar que o cérebro detenha alguma virtude esotérica, misteriosa que não pudesse ser pesquisada pela ciência. Estamos perfeitamente dentro da realidade natural e supomos que todos esses fenômenos, por mais emergenciais que possam ser, são tipicamente naturais. É possível, como sugerem Hillis e Penrose, que o atual estado da ciência não tenha metodologia, nem teoria, para dar conta desses saltos. A expectativa sobre a mecânica quântica é indicada, mas não passa, por enquanto, de hipótese. Entretanto, também poderá ocorrer, como quer Hillis, que o computador possa chegar a comportamento inteligente sem saber explicar a razão exatamente, mas conseguindo trabalhar conexões adequadas e ambientes favoráveis, exatamente como acontece conosco: sabemos pensar, mas não sabemos pensar o pensamento, no sentido de decompor sua estruturação e tessitura. 
Uma referência fundamental da inteligência é sua flexibilidade ilimitada, capaz de se sair bem em contexto complexo e difuso. Como diria Kosko (1999), a lógica binária é excepcional na vida das pessoas, exceto em ditadores que apreciam a rigidez. No dia a dia, vivemos contexto difuso, confuso, aproximativo, onde a exatidão também não é necessidade maior. Frente à realidade imprecisa, é mister saber lidar com a imprecisão do modo mais preciso possível. Encontramos aqui uma disjuntiva típica: o conhecimento conhece pela via de tornar preciso o que é impreciso, sobretudo pelo caminho analítico formal; entretanto, não pode tornar precisa a imprecisão, porque a descaracteriza, já que a imprecisão reduzida a uma lógica binária seria mera caricatura. Que fazer então? Não é o caso abandonar a expectativa binária, porque explicar é também sempre simplificar e o todo mais simples que conhecemos é aquele formado de apenas duas partes. Mas é mister saber lidar com a dinâmica complexa, mesmo tendo que catar nela padrões. Precisamos dos padrões, porque dentro da expectativa formal, só entendemos a variação descobrindo duas invariantes. Na visão de Shermer (1997, 1999), que estuda religiões e crenças e desenvolveu a idéia de que o ser humano é "máquina de crer", diante da realidade ameaçadora, confusa, pouco dominável, a primeira coisa que fazemos é buscar nela o que se repete, o recorrente, aquilo que já tínhamos visto antes, algum padrão que sempre volta e transmite a segurança de um fenômeno tratável. Assim, perante a complexidade extrema o primeiro ímpeto é simplificar, tateando algoritmos, padrões, formas. É neste sentido que a realidade nos traz informação demais, devendo-se filtrar o que interessa, ou seja, descartar a massa desnecessária. Norretranders chama a isto de "exformação", dando a entender que esta atividade é a mais fundamental do processo de informação: não é cumulativo quadradamente, armazenando o que aparece, mas seletivo, eliminativo, reducionista.

A inteligência é menos a capacidade de lidar com a certeza, do que saber sobreviver no mundo incerto. Saber pensar não é propriamente seguir instruções seqüenciais sempre as mesmas, mas contestá-las, inová-las, descartá-las, sobretudo saber enfrentar o novo, aquilo que não estava no script ou nunca se tinha visto antes. Decorar é, por isso, insanidade, porque se supõe que teremos pela frente sempre o mesmo problema, com a mesma solução. É fundamental saber questionar, pesquisar, para dar conta de contextos e referências não sabidas, reinterpretar o que já conhecemos, aprender dos outros sem se submeter. Dentro deste quadro, podemos sumariar algumas marcas da inteligência:

a) primeiro, inteligência é a capacidade de duvidar da inteligência; não é inteligente quem assim se julga; questionar é seu primeiro ato, sua essência metodológica, sobretudo autocrítica; não é inteligente quem apenas critica os outros, imaginando que nenhuma crítica lhe cabe; seria, como dizem Habermas e Apel [falta a referência a este autor], total contradição performativa, desfazendo o discurso em sua aplicação (HABERMAS, 1989); ainda vale a proposta socrática: sabe mais e melhor quem sobretudo sabe que não sabe;

b) segundo e consentâneo ao primeiro ponto, inteligência é saber de seus limites e potencialidades, para poder transformar os limites em desafios ilimitados e as potencialidades em pretensão limitada; é próprio da inteligência não parar diante de limites, mas arrostá-los, enfrentá-los, negando-se a curvar-se, ainda que saiba - plenamente - que é algo limitado; é próprio dela também, no mesmo ímpeto, acreditar-se capaz de tudo, vagando no mundo da esperança e da utopia, onde tudo pode; mas sabe que isto não é real; entretanto, se abandonasse a utopia, bastar-se-ia com as misérias historicamente dadas; é preciso construir castelos no ar, embora não para morar neles, mas para tê-los como referência crítica radical de tudo que é dado; neste sentido, inteligência é força que se ultrapassa, ingênua neste sentido, mas dotada de fogo imorredouro de vencer todas as batalhas, até mesmo a morte; por isso, o lado racional da inteligência representa a dubiedade de querer tudo poder e de poder até certo ponto;

c) terceiro, inteligência é coisa fina, sensível, suave, porque sabe andar na greta das coisas, olhar o outro lado, ultrapassar as aparências, ver além dos horizontes dados, imaginar o que seria e 
poderia ser; nossa cabeça não é armazém de dados, monturo de idéias, lixeira de resíduos, mas jardim bem plantado, dotado de desordem ordenada, padrões flexíveis, maleabilidade quase inesgotável; sabe perceber o imperceptível, farejar a pista quase apagada, interpretar do contexto, surpreender dinâmicas que apenas se insinuam; sabe estabelecer conexões surpreendentes, vislumbres inesperados, ligações aparentemente contraditórias;

d) quarto, inteligência é habilidade de estilo dialético, que usa truques binários apenas para simplificar o que lhe parece muito complicado, mas os usa para entender a fundo, não apenas o que é reto, exato, formal; não se perde na aparência, no mapa simples, no modelo acabado, mas esgueira-se no interior de realidade sinuosa, apostando na percepção sensível, buscando ecos que vão e vêm, perscrutando as dobras e volutas, realizando aproximações flexíveis sempre capazes de aprender;

e) quinto, inteligência é saber indicar erros e corrigi-los, desde aqueles que poderíamos ou deveríamos evitar, até aqueles inevitáveis, porque parte integrante da complexidade no fundo indevassável; só aprende quem sabe errar; nunca existe o acerto completo na realidade incerta, bem como não existe o erro total no campo das probabilidades emaranhadas;

f) sexto, inteligência é saber aprender, no sentido reconstrutivo político, desde aprender do que já se aprendeu, até saber saltar para o que ainda não se aprendeu; ser inteligente é ser sujeito de sua própria inteligência, como ser autônomo e cidadão, elaborar proposta própria, ser capaz de história criativa;

g) sétimo, inteligência é saber pesquisar, no sentido pedagógico do questionamento reconstrutivo, colocando em tela a capacidade de questionar e reconstruir; diante de realidade que se esconde, além de extremamente complexa, é mister sempre perguntar de novo, desfazer o que se tinha feito, desconstruir para reconstruir, começar outra vez; trata-se não só de gostar de perguntar, como sobretudo de saber perguntar, ou seja, colocar as questões corretas;

h) oitavo, inteligência é dar conta do que não tem solução, já que toda solução produz novos problemas e todo problema tem alguma solução, exceto a morte; encontrar meio termo entre o conformismo e a esquizofrenia é grande sabedoria; não podemos, nem sabemos resolver tudo, mas temos habilidade para buscar soluções, mesmo que parciais, realizando aproximações sensíveis, espertas, insinuantes; é preciso saber parar, como é também mister saber não parar, porquanto no topo só chegam os que não param, enquanto outros sequer começam a subir; esta dialética é de tessitura finíssima, porque brinca com os próprios limites da vida em sociedade, temperando a dureza da vida com esperanças por vezes ilimitadas, bem como acalmando as esperanças com as restrições do dia a dia;

i) nono, inteligência é não curvar-se a nenhum conhecimento vigente, nem ao científico, bem como escutar atentamente outros saberes, também aqueles que possuem menos afinação metodológica; não conseguimos saber tudo, porque a realidade nos ultrapassa, estamos dentro dela, ela nos abrange, não nós a ela; faz parte da inteligência sempre reservar espaço para o ainda não visto, não experimentado, não mensurado, pois, se tudo tem tantos lados, nunca damos conta de todos;

j) décimo, inteligência é saber que ninguém se emancipa sem a ajuda dos outros, mas que todo processo de emancipação precisa, ao final das contas, dispensar a ajuda, para poder andar como pernas próprias; ser sujeito não é dispensar a sociedade, mas conviver com autonomia solidária; ser inteligente é, em grande medida, ser dono do próprio pensamento, não para guardá-lo só para si, mas para realizar comunicação como sujeito. 
Ponto central da aprendizagem inteligente é o combate sem tréguas ao instrucionismo, por ser tática tipicamente reprodutiva e que reduz o aluno a objeto. A biologia também o combate fortemente, como na obra de Maturana e Varela, ao descobrirem a marca reconstrutiva de todo ser vivo, capaz de história própria dentro das circunstâncias dadas (MATURANA; VARELA, 1994; VARELA, 1997). Embora nossa história esteja marcada pelo "ensino" e que se oficializou mais que tudo na nova LDB, é fundamental compreender que a aprendizagem reconstrutiva de teor político é autenticamente educação, não mero ensino. Desta deturpação advém a redução da aprendizagem a escutar aulas apenas expositivas e reprodutivas, como é uso nas escolas e universidades, sem falar que se firmou a distinção entre o professor que ensina e o aluno que aprende. A dinâmica reconstrutiva do conhecimento lhe é intrínseca, porque elaborado, no plano da biologia, por um órgão que não saberia apenas reproduzir a realidade externa, e, no plano social, por seres interpretativos, hermeneuticamente contextuados. Neste sentido, a ambiência instrucionista da sala de aulas é uma violência cultural, porque tolhe a capacidade de inovar e saltar que toda mente humana possui. Enquanto os peritos mais críticos em computação buscam sofregamente superar o instrucionismo, porque sacaram que o problema está mais no plano das idéias do que da máquina, os professores, em sua grande maioria, continuam repassando para seus alunos "café requentado".

Com respeito à inteligência artificial, estamos assistindo a avanços expressivos, uma vez superada a euforia representacionista e a confiança excessiva em procedimentos binários lineares. De estruturas simples podem sair estruturas complexas, e vice-versa, mostrando a não linearidade da realidade, cuja organização dos componentes oferece surpresas até agora pouco decifradas. Exemplo interessante, apontado por Hillis, é a similitude dos dois hemisférios do cérebro quando olhados no microscópio, mas cujas funções parecem ser, por vezes, muito diferentes. A pergunta parece inevitável: como estruturas aparentemente tão semelhantes podem produzir fenômenos tão diversos? Os componentes físicos parecem ser os mesmos, mas estão dispostos de tal modo que geram resultados distintos. Algo parecido ocorreria com a "vida": não é substância específica ou coisa especial, mas simplesmente uma forma própria de organização da matéria. Esta perplexidade está levando a inteligência artificial a rever a linearidade dos atuais computadores, buscando, sobretudo, com o advento das redes neuronais, ambientes amigáveis com respeito à complexidade, mais capazes de aprender de modo mais flexível, aptos a lidar com o erro e sensíveis - ou pelo menos abertos - ao fenômeno da emergência. As idéias de Picard em torno da emoção nos computadores, de Prigogine com respeito à dialética da natureza, de Tapscott (1998) sobre a geração digital indicariam que o pano de fundo hermenêutico passa a fazer parte das redes neuronais eletrônicas, tendo como aceno no horizonte que não só a sociedade é hermeneuticamente contextuada, mas a própria natureza, pois não nasceu pronta nem está pronta. É perpétuo vir a ser e irreversível no tempo.

\section{Para concluir}

O ambiente virtual da aprendizagem vai crescer de modo surpreendente. Como assevera Schugurensky,

o crescimento de cursos virtuais é tão impressionante, que se chegou a especular que os avanços tecnológicos poderiam eventualmente levar à consolidação de universidades virtuais, nas quais os estudantes podem completar a graduação on-line sem colocar os pés no campus" (SCHUGURENSKY, 1999, p. 291). 
O problema que pode surgir e talvez já seja real é a tendência instrucionista avassaladora de tais cursos. Em vez de aportarmos alternativas autênticas de aprendizagem inteligente, recaímos na recuperação da aula, alargando ainda mais os espaços da instrução reprodutiva. De uma parte, parece grande avanço poder estudar de modo mais livre, onde se vive e trabalha, a qualquer hora, de outra, a tendência mercadológica pode levar aos abusos de cursos feitos para distribuir diplomas ainda menos confiáveis. Será o caso levar em conta que passou o tempo em que acreditávamos piamente nos meios eletrônicos, como se tivessem poder educativo mecânico e automático. A visão de Hillis mostra que também os pesquisadores mais avançados da área estão atrás, muito mais, de idéias do que de equipamentos.

A discussão que Hillis provoca reflete a polêmica epistemológica de fundo, hoje candente em todos os recantos da academia, por vezes entendida como ilação pós-moderna. Frente a uma realidade reconhecida como não linear, complexa, a metodologia procede de modo padronizador, inevitavelmente também deturpando a realidade, à medida que a pretende captar. Como só a capta de modo reconstrutivo, autopoiético, a realidade captada está sempre à mercê do observador. O computador dá a impressão contrária, quando procede de modo algorítmico e seqüencial, sugerindo uma simplicidade absoluta por baixo da complexidade. Hoje sabemos que esta simplificação é apenas truque metodológico. A inteligência humana é fundamentalmente semântica, indo, pois, muito além das bases sintáticas. Para o computador tornar-se inteligente, deveria tornar-se semântico. Digamos que seja possível, mas ainda não descobrimos isso na máquina.

\section{Referências}

BERMAN, M. Tudo o que é sólido desmancha no ar: a aventura da modernidade. São Paulo: Companhia das Letras, 1986.

COLLINS, R. The sociology of philosophies: a global theory of intellectual change. Cambridge, MA: The Belknap Press of Harvard University Press, 1998.

DREYFUS, H. L. What computerss Still can't do: a critique of artificial reason. Cambridge, MA: The MIT Press, 1997.

HABERMAS, J. Consciência moral e agir comunicativo. Rio de Janeiro: Tempo Brasileiro, 1989.

HILLIS, W. D. The pattern on the stone: the simple ideas that make computers work. New York: Basic Books, 1998.

HOFSTADTER, D. R. Gödel, Escher, Bach: um entrelaçamento de gênios brilhantes. Brasília: Ed. UnB, 2001.

KOSKO, B. The fuzzy future: from society and science to heaven in a chip. New York: Harmony Books, 1999.

KURZWEIL, R. The age of spiritual machines: when computers exceed human intelligence. New York: Viking, 1999.

MATURANA, H.; VARELA, F. De máquinas y seres vivos: autopoiesis: la organización de lo vivo. Santiago: Editorial Universitaria, 1994. 
NORRETRANDERS, T. The user illusion: cutting consciousness down to size. New York: Penguin Books, 1998.

PENROSE, R. Shadows of the mind: a search for the missing science of consciousness. New York: Oxford University Press, 1994.

PICARD, R. W. Affective computing. Cambridge, MA: The MIT Press, 1999.

PRIGOGINE, I. O fim das certezas: tempo, caos e as leis da natureza. São Paulo: Ed. Unesp, 1996.

PRIGOGINE, I.; STENGERS, I. A nova aliança. Brasília: Ed. UnB, 1997.

SCHUGURENSKY, D. Higher education restructuring in the era of globalization: toward a heteronomous model? In: ARNOVE, R.F.; TORRES, C. A. Comparative education: the dialectic of the global and the local. New York: Rowman \& Littlefield, 1999.

SEARLE, J. R. O mistério da consciência. Rio de Janeiro: Paz e Terra, 1998.

SFEZ, L. Crítica da comunicação. São Paulo: Loyola., 1994.

SHERMER, M. Why people believe weird things: pseudoscience, superstition, and other confusions of our time. New York: W. H. Freeman and Company, 1997.

SHERMER, M. How we believe: the search of God in an age of science. New York: W. H. Freeman and Company, 1999.

TAPSCOTT, D. Growing up digital: the rise of the net generation. New York: McGraw-Hill, 1998.

VARELA, F. J. et al. The embodied mind: cognitive science and human experience. Cambridge, MA: The MIT Press, 1997. 